Bond University

Research Repository

\title{
Effect of Drinking Rate on the Retention of Water or Milk Following Exercise-Induced Dehydration
}

Sayer, Liam; Rodriguez-Sanchez, Nidia; Rodriguez-Giustiniani, Paola; Irwin, Christopher; McCartney, Danielle; Cox, Gregory R; Galloway, Stuart D R; Desbrow, Ben

Published in:

International Journal of Sport Nutrition and Exercise Metabolism

DOI:

10.1123/ijsnem.2019-0176

Licence:

Other

Link to output in Bond University research repository.

Recommended citation(APA):

Sayer, L., Rodriguez-Sanchez, N., Rodriguez-Giustiniani, P., Irwin, C., McCartney, D., Cox, G. R., Galloway, S. D. R., \& Desbrow, B. (2020). Effect of Drinking Rate on the Retention of Water or Milk Following ExerciseInduced Dehydration. International Journal of Sport Nutrition and Exercise Metabolism, 30(2), 128-138. https://doi.org/10.1123/ijsnem.2019-0176

\section{General rights}

Copyright and moral rights for the publications made accessible in the public portal are retained by the authors and/or other copyright owners and it is a condition of accessing publications that users recognise and abide by the legal requirements associated with these rights.

For more information, or if you believe that this document breaches copyright, please contact the Bond University research repository coordinator. 


\section{Introduction}

Individuals typically do not consume enough fluid during exercise to counteract sweat losses, producing a post-exercise state of body water deficit (i.e. dehydration) (Garth \& Burke, 2013). As a result, individuals are encouraged to drink fluid during recovery to reinstate total body water balance prior to recommencing physical activity (Evans et al., 2017; Sawka et al., 2007). However, rapidly consuming large volumes of hypotonic fluid has the potential to reduce plasma osmolality (POSM), resulting in increased urinary output (i.e. "fluid induced diuresis"), potentially delaying a return to euhydration (Mitchell et al., 1994;

Robertson, 1974). Hence, there is considerable scientific interest in understanding factors that enhance fluid retention and assist with rehydration after exercise.

When consumed without food and matched for volume, nutrient dense beverages (e.g. milk and milkbased beverages) appear to promote greater fluid retention compared to water and carbohydrateelectrolyte solutions (Desbrow et al., 2014; Seery \& Jakeman, 2016; Shirreffs et al., 2007; Watson et al., 2008). The effectiveness of milk as a rehydration solution has been attributed to a number of its constituents (i.e. sodium (Merson et al., 2008; Shirreffs \& Maughan, 1998), carbohydrate (Osterberg et al., 2009), and protein (Hobson \& James, 2015; James et al., 2014; James et al., 2012)), which are believed to delay gastric emptying and/or attenuate changes in $\mathrm{P}_{\mathrm{OSM}}$, reducing the degree of fluid induced diuresis (Calbet \& MacLean, 1997; Clayton et al., 2014; Murray et al., 1999; Vist \& Maughan, 1995).

Typically, post-exercise rehydration studies control drinking rate by prescribing fixed volumes of beverages within standardised time periods. In contrast, active individuals may consume fluids at different rates, which is likely to influence nutrient delivery and consequently, fluid retention. To date, only two studies have investigated the influence of drinking rate on fluid recovery (Jones et al., 2010; Kovacs et al., 2002). The initial investigation failed to detect differences in fluid retention when a carbohydrate-electrolyte beverage was consumed over $3 \mathrm{~h}(79 \pm 6 \%)$ compared to $5 \mathrm{~h}(82 \pm 5 \%)$ following exercise-induced dehydration (3.0\% body mass (BM) loss). In contrast, Jones et al., (2010) reported significantly greater retention when water was consumed over a $4 \mathrm{~h}(75 \pm 12 \%)$ compared to a $1 \mathrm{~h}$ 
$(55 \pm 18 \%)$ drinking period following an exercise-induced $2.0 \% \mathrm{BM}$ loss. The explanation for the equivocal findings may relate to the subtle differences in the drinking rates and/or the use of beverages with different nutrient profiles (and hence osmolalities). Furthermore, when consumed ad libitum, individuals typically ingest the largest volume of fluid within the first $30 \mathrm{~min}$ following exercise (Baguley et al., 2016). To date, the effect of drinking rate on the retention of fluid from beverages with contrasting nutrient profiles has not been systematically examined. In addition, no previous investigation has compared a conservative drink pattern to a rapid ingestion rate (e.g. large volumes consumed in $\sim 30 \mathrm{~min}$ ), which may reflect the actual behavior of individuals following exercise.

Therefore, the aim of the current study was to investigate the effect of rapid vs slower drinking rates on fluid retention using beverages with contrasting nutrient profiles (milk vs. water). It was hypothesized that the fluid retained from the consumption of a nutrient dense beverage would be unaffected by drinking rate; and that slower intake of a hypotonic beverage would enhance subsequent fluid retention.

\section{Methods}

\section{Overview of study designs}

This investigation was intended to systematically explore the effect of drinking rate on subsequent fluid recovery. The investigation was conducted in two parts, with the results from Part A used to inform the design of Part B. Part A explored the impact of drinking rates of different beverages (milk and water) on fluid retention. In Part B, further exploration of different drinking rates was performed. In addition, the trials were conducted in separate laboratories (Part A - Australia, Part B - Scotland). All participants were fully informed of the nature and possible risks of the investigations before providing written informed consent. The investigation was approved by the Griffith University and University of Stirling's Human

Ethics Committees and the procedures were conducted in accordance with the principles outlined by the declaration of Helsinki.

\section{Participant characteristics}


50 In Part A thirteen healthy males volunteered to take part. However, one participant was unable to continue

51 with the study after completing the first trial for reasons unrelated to the study (i.e. work commitments).

52 Consequently, twelve male participants (age: $23.5 \pm 5.3 \mathrm{y}$; height: $179 \pm 6 \mathrm{~cm}$; BM: $77.3 \pm 9.6 \mathrm{~kg}$; maximal

54 In Part B fourteen healthy participants volunteered to take part. However, one participant withdrew from oxygen consumption $\left.\left(V O 2_{\text {peak }}\right): 43.1 \pm 6.4 \mathrm{~mL} \cdot \mathrm{kg}^{-1} \cdot \mathrm{h}^{-1}(\mathrm{Mean} \pm \mathrm{SD})\right)$ completed four experimental trials. the study due to external factors and one participant's data was excluded because they could not achieve the required level of dehydration. Consequently, twelve ( 9 males and 3 females) participants (age: $28.3 \pm 6.3 \mathrm{y}$; height: $176 \pm 11 \mathrm{~cm} ;$ BM $\left.74.0 \pm 10.2 \mathrm{~kg} ; V O 2_{\text {peak }}: 50.6 \pm 7.6 \mathrm{~mL} \cdot \mathrm{kg}^{-1} \cdot \mathrm{h}^{-1}\right)$ completed four experimental trials.

\section{Study designs}

A schematic representation of the experimental protocols is displayed in Figure 1. Both parts utilised a repeated-measures experimental design, involving 4 experimental trials; each separated by a minimum of $5 \mathrm{~d}$. For all trials, participants lost $\sim 2.0 \%$ BM through intermittent cycle exercise before cooling down and beginning a rehydration period in which different treatment interventions were examined (Part A, water or milk ingested over 30 or $90 \mathrm{~min}$; Part B, water ingested over 15, 45, or $90 \mathrm{~min}$ with either the 15 or 45 min trial repeated). An incomplete Latin square design was used to counterbalance the order of treatments.

\section{Preliminary requirements}

Participants undertook an incremental test to exhaustion on a cycle ergometer. The protocol began at 100

$\mathrm{W}$, and increased in $50 \mathrm{~W}$ increments every $2.5 \mathrm{~min}$ until volitional exhaustion, with participant's breath sampled continuously via a calibrated gas analysis system (Part A: Medgraphics Ultima, USA; Part B:

Servomex Group Ltd, United Kingdom ). The test was used to determine $\mathrm{VO}_{\text {peak }}$ and maximum heart rate $\left(\mathrm{HR}_{\max }\right)$, with these values used to guide the prescription of exercise intensity for the experimental trials.

Participants were instructed to abstain from caffeine (12 h), alcohol (24 h) and moderate to strenuous exercise $(12 \mathrm{~h})$ before all trials. During the $24 \mathrm{~h}$ period preceding the first trial, individuals completed a 
food and beverage diary. They were also instructed to drink $500 \mathrm{~mL}$ of water at least $2 \mathrm{~h}$ before arrival at the laboratory (to assist with hydration) and abstain from all food and fluid (excluding water) after 21:00 h. Individuals were then instructed to repeat these behaviors prior to all subsequent experimental trials.

\section{Experimental procedures}

Participants arrived at the laboratory between 05:30 and 08:00 $\mathrm{h}$ and verbally acknowledged compliance to the pre-experimental conditions. A urine sample was taken for determination of hydration status (Part A: urine specific gravity $\left(\mathrm{U}_{\mathrm{SG}}\right)$ (Palette Digital Refractometer, ATAGO, USA) and Part B: urine osmolality ( $\mathrm{U}_{\mathrm{OSM}}$ ) (Löser Osmometer, Camlab, UK). If participants recorded a $\mathrm{U}_{\mathrm{SG}} \geq 1.024$ (Sommerfield et al., 2016) or $\mathrm{U}_{\mathrm{OSM}}$ of $>700 \mathrm{mOsm} \cdot \mathrm{kg}^{-1}$ (Sawka et al., 2007) they were considered hypohydrated. In Part A, hypohydrated participants were required to consume $600 \mathrm{~mL}$ of plain water over $5 \mathrm{~min}$, before providing a second urine sample 30-60 min later. If this urine sample achieved the thresholds for euhydration the participants continued with the trial (this practice was then replicated on all subsequent trials). If the threshold value was not reached within the $60 \mathrm{~min}$ period the trial was rescheduled. Participants then rested in a seated position for 5 min prior to venepuncture of a forearm vein. Following this initial blood collection, participants were provided with a standardised breakfast in a quantity relative to $\mathrm{BM}(20 \mathrm{~kJ} \cdot \mathrm{kg}-1$ and $1 \mathrm{~g} \mathrm{CHO} \cdot \mathrm{kg}-1)$ that consisted of raisin toast, strawberry jam and fruit juice (200 before completing a questionnaire on GI subjective symptoms, voiding their bladder and obtaining a baseline nude BM measurement (Part A: A\&D Company Ltd, Tokyo, Japan, to nearest 20 g; Part B: Marsden, Rotherham, United Kingdom, to nearest $10 \mathrm{~g}$ ).

\section{Exercise-induced dehydration}

After completing a brief standardised warm up, participants began cycling in a warm environment (Part A: $25.2 \pm 0.8{ }^{\circ} \mathrm{C}$ and $84 \pm 11 \% \mathrm{RH}$, Part B: $26.4 \pm 0.7^{\circ} \mathrm{C}$ and $\left.38 \pm 5 \% \mathrm{RH}\right)$. Individuals commenced exercise at a workload corresponding to $\sim 65 \%$ of $\mathrm{HR}_{\max }$. Intensity was recorded by an investigator and replicated on all subsequent trials. Following 50 min of cycling, participants BM was measured. A BM loss of $<1.8 \%$ from baseline required participants to continue exercising in 10 min bouts until a $\mathrm{BM}$ loss $\geq 1.8 \%$ was 
achieved. Following exercise, dehydrated participants rested in a seated position for 15 min prior to having a cool shower. Afterwards, participants dried themselves thoroughly, before a cannula was inserted into a forearm vein and a blood sample obtained. Participants then emptied their bladder and provided a urine sample before a final nude BM measure was recorded to determine total fluid loss (30 min post-exercise).

\section{Post-exercise fluid replacement}

In Part A, water or low fat cow's milk (Maleny Dairies, Queensland, Australia; 210 kJ Energy, 5.3 g CHO, $4.0 \mathrm{~g}$ Protein, $1.4 \mathrm{~g}$ Fat, $48 \mathrm{mg} \mathrm{Na}^{+} \cdot 100 \mathrm{~mL}^{-1}$ ) were ingested in a quantity equal to $100 \%$ of the volume of sweat lost during exercise. The fluid volume was ingested in six equal aliquots spread evenly over either a 30 or $90 \mathrm{~min}$ period, resulting in the beverage treatments: Water $30 \mathrm{~min}$ (W30), Water 90 min (W90), Milk 30 min (M30), and Milk 90 min (M90). Participants were instructed to consume each aliquot at an even pace over 5 or 15 min according to the relevant drinking rate. In Part B, water in a quantity equal to $100 \%$ of the volume of sweat lost during exercise was ingested. The volume was provided in three aliquots spaced evenly over either a 15,45 or 90 min drinking period, resulting in the following beverage treatments: Water $15 \mathrm{~min}$ (DR15); Water $45 \mathrm{~min}$ (DR45); and Water 90 min (DR90). To assess within individual variation, participants in part B repeated either the DR15 or DR45 trial. To assess inter-site variation W90 (Part A) was compared to DR90 (Part B).

A $3 \mathrm{~h}$ rehydration monitoring period (from the commencement of drinking) was applied to all trials. Observations were made every hour and included measures of nude BM, urine and plasma measures of hydration status. In addition, subjective measures of bloatedness, fullness and thirst were recorded. All measurements were obtained while participants remained seated.

\section{Body mass and fluid retention}

BM change (estimate of fluid loss) was calculated by subtracting the post-exercise BM (post-void) from the pre-exercise BM. Net BM change was calculated by subtracting the $3 \mathrm{~h}$ BM measurement from the 
pre-exercise BM. Percent fluid retention at the conclusion of the observation period was calculated by the following equation:

Fluid Retained $(\%)=100 \times \quad$ (Total beverage ingested $(\mathrm{g})-$ Total urine output $(\mathrm{g}))$

Total beverage ingested $(\mathrm{g})$

\section{Urine and blood collection, storage and analysis}

Additional urine sampling was performed at pre-exercise, post-exercise (immediately pre-drinking), immediately post-drinking and then at $120 \mathrm{~min}$ and $180 \mathrm{~min}$ after the start of drinking. At each of these urine collection points, participants completely voided their bladder into an empty container for subsequent measures of urine volume. Total urine loss was calculated from the accumulated urine output in the period from the commencement of drinking until the end of the observation period. A sample of urine was retained for determination of urine osmolality. Blood sampling was performed at pre-exercise, post-exercise (immediately pre-drinking), immediately post-drinking and then at $120 \mathrm{~min}$ and $180 \mathrm{~min}$ after the start of drinking for the determination of $\mathrm{P}_{\mathrm{OSM}}$. Participants remained seated prior to a $5 \mathrm{~mL}$ blood sample being drawn from an antecubital vein. All samples were collected into EDTA pre-treated vacutainers and centrifuged at room temperature for $10 \mathrm{~min}$ at $\sim 1350 \times \mathrm{g}$. Plasma was analysed in duplicate on a calibrated freezing-point depression osmometer (Part A: Osmomat 030, Germany and Part B: Löser osmometer, Camlab, UK). Cannulas were kept patent by flushing sterile saline ( $2 \mathrm{~mL}$ of $0.9 \%$ $\mathrm{NaCl}$; Becton Dickson, NJ, USA) on completion of each sample (with an equivalent volume of blood initially discarded before collection of subsequent samples).

\section{Subjective measures}

Subjective ratings of bloatedness, fullness and thirst were recorded on separate $100 \mathrm{~mm}$ visual analog scales, with $0 \mathrm{~mm}$ representing 'not at all' and $100 \mathrm{~mm}$ representing 'extremely'. Scales were administered via a computerized modifiable software program (Marsh-Richard et al., 2009). 


\section{Statistical analyses}

Statistical analyses were performed using SPSS Statistics for Windows, Version 22 (SPSS Inc., IBM, Chicago, IL). All measures were examined for normality and sphericity using the Shapiro-Wilk test $(p>0.05)$ and Mauchly's test $(p>0.05)$, respectively. Where assumptions of sphericity in repeatedmeasures analyses were violated, the Greenhouse-Geisser statistic was applied. One-way repeatedmeasures analysis of variance (ANOVA) were performed to verify that pre-trial conditions and exerciseinduced fluid loss did not differ across trials. For Part A, a three-factor (i.e. Beverage $\mathrm{x}$ Rate $\mathrm{x}$ Time) repeated-measures ANOVA was used to compare main outcomes; two-factor (i.e. Beverage $\mathrm{x}$ Rate) repeated-measures ANOVA were conducted to compare total fluid retention and net BM changes across treatments. Pairwise comparison (Bonferroni) were performed where significant main effects were present. For Part B, two-factor (i.e. Rate x Time) repeated-measures ANOVA were used to compare outcomes between the different beverage ingestion rates. Paired $t$-tests or Wilcoxon tests were used where appropriate to conduct post-hoc comparisons on significant interaction effects. An adjusted-alpha (i.e. $p=0.05$ divided by the number of tests performed) was used to account for multiple comparisons. The test-retest reliability was calculated as a coefficient of variation (CV\%) using the traditional method and any difference in responses between sites was assessed using an unpaired $t$-test. Statistical significance was accepted at $p<0.05$. All data are reported as Mean $\pm \mathrm{SD}$, unless stated as Mean $\pm \mathrm{SEM}$.

\section{Results}

\section{Standardisation procedures}

All participants reported compliance with the standardisation procedures in the $24 \mathrm{~h}$ prior to arriving at the laboratory. In Part A, two participants were administered water $(600 \mathrm{~mL})$ due to a pre-exercise USG $\geq 1.024$ on Trial 1 ; this practice was repeated on all subsequent trials to ensure consistency. The remaining participants had a $\mathrm{U}_{\mathrm{SG}}<1.024$ at the commencement of each trial. Exercise duration and pre-exercise values for $\mathrm{BM}, \mathrm{U}_{\mathrm{SG}}$ and $\mathrm{P}_{\mathrm{OSM}}$ were similar across all treatments, and did not differ significantly by trial order $(\mathrm{p}>0.05)$. Exercise-induced BM loss differed significantly $(\mathrm{p}<0.01)$ by trial order (Trial 1: 
$171 \quad 1.54 \pm 0.26 \mathrm{~kg}$; Trial 2: $1.44 \pm 0.28 \mathrm{~kg}$; Trial 3: $1.41 \pm 0.31 \mathrm{~kg}$; Trial 4: $1.38 \pm 0.32 \mathrm{~kg}$ ); however,

172 counterbalancing ensured that mass loss was similar across treatment conditions (Table 1).

173 In Part $\mathrm{B}$, exercise duration and pre-exercise values for $\mathrm{BM}, \mathrm{U}_{\mathrm{OSM}}, \mathrm{P}_{\mathrm{OSM}}$, and exercise induced $\mathrm{BM}$ loss

174 were similar across all treatments (Table 1); and did not differ significantly by trial order $(\mathrm{p}>0.05)$.

175 Urine output and fluid retention

176 In Part A, cumulative urine output was greater with water than with milk at $120 \mathrm{~min}(398 \pm 190 \mathrm{vs.} 139 \pm 44$

$177 \mathrm{~g})$ and $180 \mathrm{~min}(592 \pm 248$ vs. $224 \pm 70 \mathrm{~g})$ after the start of drinking $(p<0.01$; Figure $2 \mathrm{~A})$. A significant

178

179

180

181

182

183

184

185

186

187

188

189

190

191

192

193

effect of beverage was observed on fluid retention (W30: 56.5 $16.1 \%$; W90: $59.7 \pm 19.9 \%$; M30: $82.9 \pm 6 \%$; M90: $84.9 \pm 7 \%$ ) with the proportion of ingested fluid retained lower with water than milk $(58.1 \pm 15.6$ vs. $83.9 \pm 6.1 \%, p<0.01)$. No other significant differences were observed in either analysis.

In Part B, a similar cumulative urine output response was observed when water was ingested at DR15, DR45 and DR90 rates. Three hours after the start of the drinking period, cumulative urine output was lower for the DR90 trial (602 $\pm 183 \mathrm{~g})$ compared to the DR45 (750 $\pm 373 \mathrm{~g})$ and DR15 (754 $\pm 230 \mathrm{~g})$ trials, but this did not reach statistical significance $(\mathrm{p}>0.05)$. The mean difference $(95 \% \mathrm{CI})$ between DR15 and DR90 was 7.4(1.2-13.6)\%, equivalent to $152(43-260) \mathrm{mL}$ (Figure 2B). Fluid retention was significantly higher $(p<0.05)$ on the DR90 trial $(57.1 \pm 12.9 \%)$ compared to the DR15 trial $(49.7 \pm 11.0 \%)$, but these trials were not different $(\mathrm{p}>0.05)$ to DR45 $(51.6 \pm 19.8 \%)$.

\section{Net fluid balance}

In Part A, all experimental trials concluded with participants in a state of negative net fluid balance 180 min after the ingestion period started (Part A: W30: $-0.68 \pm 0.31 \mathrm{~L}$; W90: $-0.61 \pm 0.25 \mathrm{~L} ; \mathrm{M} 30$ : $-0.27 \pm 0.07$ L, M90: $-0.28 \pm 0.08$ L; Figure 3A). Post hoc comparisons revealed that milk ingestion led to less negative fluid balance compared to water at $120 \mathrm{~min}(-0.40 \pm 0.19$ vs. $-0.14 \pm 0.04 \mathrm{~L}, p=0.001)$ and $180 \mathrm{~min}(-$ $0.64 \pm 0.27$ vs. $-0.28 \pm 0.07 \mathrm{~L}, p<0.001)$ after drinking started. Fluid balance was also less negative 
194

immediately post-drinking for the $30 \mathrm{~min}$ compared to the 90 min drinking trials $(-0.14 \pm 0.08$ vs. $0.04 \pm 0.03 \mathrm{~L}, p<0.001$ ), since participants had less time to produce urine on these trials.

In Part B, all experimental trials concluded with participants in a state of negative net fluid balance (DR15: $-0.75 \pm 0.23$ L; DR45: $-0.75 \pm 0.37$ L; DR90: $-0.60 \pm 0.18$ L; Figure $3 B$ ). No differences were observed between trials.

\section{Plasma osmolality}

In Part $\mathrm{A}$, the consumption of water decreased $\mathrm{P}_{\mathrm{OSM}}$ compared to milk at the cessation of drinking $(291 \pm 4$ vs. $298 \pm 5 \mathrm{mOsm} \cdot \mathrm{kg}^{-1}, p<0.001$ ), but this effect was not evident by $180 \mathrm{~min}$ (Water: $290 \pm 2 \mathrm{mOsm} \cdot \mathrm{kg}^{-1}$; Milk: $\left.293 \pm 4 \mathrm{mOsm} \cdot \mathrm{kg}^{-1}, p=0.033\right)$. $\mathrm{P}_{\mathrm{OSM}}$ did not differ significantly as a result of the fluid ingestion rate at any point $(\mathrm{p}>0.05)$.

In Part $\mathrm{B}$, a drinking rate by time interaction was not evident for $\mathrm{P}_{\mathrm{OSM}}$. Plasma osmolality 180 minutes after start of drink ingestion did not differ significantly as a result of the fluid ingestion rate (DR15: $304 \pm 2 \mathrm{mOsm} \cdot \mathrm{kg}^{-1}$; DR45: $302 \pm 3 \mathrm{mOsm} \cdot \mathrm{kg}^{-1}$; DR90: $\left.303 \pm 5 \mathrm{mOsm} \cdot \mathrm{kg}^{-1}, \mathrm{p}>0.05\right)$.

\section{Subjective measures}

In Part A, analysis for bloatedness, fullness, and thirst ratings identified a significant effect of time on each variable $(p<0.01)$. A significant effect of beverage was also observed for fullness $(p=0.022)$. For bloatedness and fullness there were significant time $\mathrm{x}$ beverage interaction effects (bloatedness: $p=0.014$; fullness $p<0.01)$. Post hoc comparisons revealed that the 30 min drinking protocol increased feelings of bloatedness $(p<0.01)$ and decreased feelings of thirst $(p<0.01)$ immediately after drinking compared to the 90 min protocol. The consumption of milk increased feelings of fullness immediately after drinking $(p<0.01)$ and at $120 \mathrm{~min}(p<0.01)$, compared to the consumption of water. No other significant differences were observed.

In Part B, perceived bloatedness and fullness were significantly higher immediately after drinking on the DR15 trials compared to the DR45 and DR90 drinking rates $(p<0.01)$, but were not different at 
The CV\% of test re-test reliability between duplicate trials on DR15 and DR45 ingestion rates (Part B) was $17 \%$. Data from repeated trials was not significantly different (Table 2). The fluid retention on 90 min water rate trials (Part A: W90 and Part B: DR90) was not significantly different between testing sites (W90: 59.7 $\pm 19.9 \%$; DR90: $57.1 \pm 12.9 \%, p=0.73$ ).

\section{Discussion}

This two-part study explored the effect of drinking rate on fluid retention of different beverages following exercise-induced dehydration. In keeping with our hypothesis, Part A observed that drinking milk resulted in greater fluid retention than water during a $3 \mathrm{~h}$ recovery period. This effect was not influenced by drinking rate (i.e. 30 vs. $90 \mathrm{~min}$ ). Consequently, Part B assessed retention of water consumed over alternative drinking rates (i.e. 15 vs. 45 vs. $90 \mathrm{~min}$ ), as well as the day-to-day variation in post-exercise fluid retention. Part B, indicated that the 15 min drinking protocol led to a significant reduction in fluid retention compared to the 90 min drinking protocol. However, the magnitude of the effect was within the $\mathrm{CV} \%$ of the repeated trials (17\%). Thus, findings from this study suggest the influence of drinking rate on post-exercise fluid recovery is small and that the nutrient composition of a beverage has a more pronounced impact on fluid retention than the beverage ingestion rate.

Only two studies have previously investigated the influence of drinking rate on fluid recovery (Jones et al., 2010; Kovacs et al., 2002). Results from these studies are contradictory, with only one investigation (Jones et al., 2010) identifying an influence of drinking rate on fluid retention. Jones et al., (2010) had participants ingest water at $1.61 \mathrm{~L}^{-1}$ vs. $0.40 \mathrm{~L} \cdot \mathrm{h}-1$. Kovacs et al., (2002) had participants ingest a carbohydrate-electrolyte sports drink at a maximum rate of $1.32 \mathrm{~L} \cdot \mathrm{h}^{-1}$ in the first hour, with an average rate over 3 hours of $0.77 \mathrm{~L} \cdot \mathrm{h}^{-1}$ and compared this to fluid retention with a slow drinking rate of $0.53 \mathrm{~L} \cdot \mathrm{h}^{-1}$ over $5 \mathrm{~h}$. These fluid consumption patterns are slower than those observed when individuals drink ad 
libitum post-exercise (e.g. with drinking rates in the first $30 \mathrm{~min}$ exceeding $2 \mathrm{~L} \cdot \mathrm{h}^{-1}$, Baguley et al., 2016).

The present study attempted to assess drinking rates across a broader range $\left(5.84 \mathrm{~L}^{-1} \cdot(1.46 \mathrm{~L}\right.$ in $15 \mathrm{~min})$ to $0.95 \mathrm{~L}^{-1}(1.42 \mathrm{~L}$ in $\left.90 \mathrm{~min})\right)$ to elucidate effects on fluid retention. We observed little impact of contrasting drinking rates on fluid retention with water. In fact, the only difference noted in Part B (DR15 vs. DR90) was within the CV\% of the method.

The current findings suggest that the nutrient profile of different beverages have a greater impact on fluid retention than ingestion rate. Indeed, when consumed exclusively and matched for volume, milk beverages promote greater fluid retention than water at rest (Maughan et al., 2016) and during the postexercise period (Seery \& Jakeman, 2016; Shirreffs et al., 2007; Watson et al., 2008). These effects may be mediated by the composition of milk (whey/casein protein), electrolyte content and insulin response to carbohydrate/protein delivery. In addition, the electrolyte content of milk (Shirreffs et al., 2007) and insulin mediated impacts on renal water transport (Magaldi et al., 1994) both have the potential to enhance fluid retention.

In a practical sense post-exercise, athletes typically consume fluids ad libitum and the beverage choice, drinking rate and total volume consumed are determined by many factors, including prior exercise (intensity, duration and type), environmental conditions, thirst, palatability, gastrointestinal tolerance, drink availability, exercise commitments and other, unrelated dietary goals (Minehan et al., 2002; Passe et al., 2000). The rapid consumption of large volumes of milk or water during the immediate post-exercise period may be poorly tolerated by some individuals. However, the range of subjective responses to our most rapid drinking rates highlights individual differences in tolerance. For those who drink beverages rapidly in the immediate post-exercise period, the rates examined in the present study do not appear to compromise fluid retention when a fixed volume is provided and may facilitate the consumption of other fluids after completing a "prescribed" volume of a beverage. Conversely, it is not known whether rapid beverage ingestion compromises subsequent voluntary fluid consumption in ad libitum drinking scenarios due to an action on thirst response mediated via the gut-brain axis (Zimmerman et al., 2019). 
Several methodological limitations require acknowledgement. Firstly, this study did not employ a direct measure of gastric emptying. Hence, while greater fluid retention was achieved during Milk trials, the distribution of the retained fluid (e.g. within the GI tract (as potentially indicated by higher "fullness" ratings) as opposed to vascular space) and therefore physiological relevance of this fluid retention remains unknown. In addition, the recovery period for this study ( $3 \mathrm{~h}$ from the start of drinking) was shorter than previous work in this area (typically $\geq 4 \mathrm{~h}$ ), which may have resulted in small volumes of uncaptured fluid losses in response to the differences in drinking strategy. The decision to shorten the duration of the observation was based on a number of factors; (1) the relatively small volumes of urine seen beyond 90 min following the cessation of drinking in our previous study (Desbrow et al 2014), (2) the smaller volume of fluid being ingested (100\% vs. $150 \%$ fluid replacement), (3) the practical relevance of $4 \mathrm{~h}$ observation, given that many individuals are likely to eat/drink within this period of time and (4) our previous study (Maughan et al., 2016) demonstrated the pattern of response in cumulative urine output and calculated hydration index to ingested drinks was observed to be similar at $2 \mathrm{~h}$ post-drinking and $4 \mathrm{~h}$ post-drinking.

\section{Conclusion}

This study suggests that drinking more rapidly does not compromise post-exercise fluid retention following moderate intensity exercise in recreationally active participants. This observation was consistent between different testing sites and across different drinking rates. Laboratory informed findings suggest that beverage composition is more influential than fluid ingestion rate in determining postexercise fluid retention.

\section{Acknowledgments}

The authors declare no conflicts of interest.

B. Desbrow and S. D. R. Galloway conceived the project. B. Desbrow, S. D. R. Galloway, G. R. Cox, C. Irwin, N. Rodriguez-Sanchez, D. McCartney, P. Rodriguez-Giustiniani and L. Sayer developed the overall research plan. L. Sayer, D. McCartney, C. Irwin, N. Rodriguez-Sanchez and P. Rodriguez- 
Giustiniani conducted the research and analysed the samples. B. Desbrow, S. D. R. Galloway, C. Irwin, N. Rodriguez-Sanchez, D. McCartney and L. Sayer performed the statistical analysis. B. Desbrow, S. D. R. Galloway, G. R. Cox, C. Irwin, N. Rodriguez-Sanchez, D. McCartney, P. Rodriguez-Giustiniani and L. Sayer wrote the paper. All the authors approved the final version of the paper.

\section{References}

Baguley, B. J., Zilujko, J., Leveritt, M. D., Desbrow, B., \& Irwin, C. (2016). The effect of ad libitum consumption of a milk-based liquid meal supplement vs. a traditional sports drink on fluid balance after exercise. International Journal of Sport Nutrition and Exercise Metabolism, 26(4), 347-355.

Baker, L. B., \& Jeukendrup, A. E. (2014). Optimal composition of fluid-replacement beverages. Comprehensive Physiology. 4(2), 575-620.

Borg, G. A. (1973). Perceived exertion: a note on "history" and methods. Medicine and Science in Sports, $5(2), 90-93$.

Calbet, J., \& MacLean, D. (1997). Role of caloric content on gastric emptying in humans. The Journal of Physiology, 498(2), 553-559.

Clayton, D. J., Evans, G. H., \& James, L. J. (2014). Effect of drink carbohydrate content on postexercise gastric emptying, rehydration, and the calculation of net fluid balance. International Journal of Sport Nutrition and Exercise Metabolism, 24(1), 79-89.

Desbrow, B., Jansen, S., Barrett, A., Leveritt, M. D., \& Irwin, C. (2014). Comparing the rehydration potential of different milk-based drinks to a carbohydrate-electrolyte beverage. Applied Physiology, Nutrition, and Metabolism, 39(12), 1366-1372.

Evans, G. H., James, L. J., Shirreffs, S. M., \& Maughan, R. J. (2017). Optimizing the restoration and maintenance of fluid balance after exercise-induced dehydration. Journal of Applied Physiology, 122(4), 945-951.

Evans, G. H., Shirreffs, S. M., \& Maughan, R. J. (2009). Postexercise rehydration in man: the effects of carbohydrate content and osmolality of drinks ingested ad libitum. Applied Physiology, Nutrition, 
and Metabolism, 34(4), 785-793.

Garth, A. K., \& Burke, L. M. (2013). What do athletes drink during competitive sporting activities? Sports Medicine, 43(7), 539-564.

Goulet, E. D., Lamontagne-Lacasse, M., Gigou, P.-Y., Kenefick, R. W., Ely, B. R., \& Cheuvront, S. (2010). Pre-exercise Hypohydration Effects On Jumping Ability And Muscle Strength, Endurance And Anaerobic Capacity: A Meta-analysis: 1681. Medicine \& Science in Sports \& Exercise, 42(5), 362.

Hobson, R., \& James, L. (2015). The addition of whey protein to a carbohydrate-electrolyte drink does not influence post-exercise rehydration. Journal of Sports Sciences, 33(1), 77-84.

James, L. J., Gingell, R., \& Evans, G. H. (2012). Whey protein addition to a carbohydrate-electrolyte rehydration solution ingested after exercise in the heat. Journal of Athletic Training, 47(1), 61-66.

James, L. J., Mattin, L., Aldiss, P., Adebishi, R., \& Hobson, R. M. (2014). Effect of whey protein isolate on rehydration after exercise. Amino Acids, 46(5), 1217-1224.

Jones, E. J., Graham, J., Newcomb, T., \& Frischman, N. (2010). Effects of Bolus vs. Metered Rehydration Rates on Fluid Retention and Hydration Efficiency using 150\% Fluid Replacement: 2290. Medicine \& Science in Sports \& Exercise, 42(5), 575.

Kovacs, E. M., Schmahl, R. M., Senden, J. M., \& Brouns, F. (2002). Effect of high and low rates of fluid intake on post-exercise rehydration. International Journal of Sport Nutrition and Exercise Metabolism, 12(1), 14-23.

Magaldi, A., Cesar, K., \& Yano, Y. (1994). Effect of insulin on water and urea transport in the inner medullary collecting duct. American Journal of Physiology-Renal Physiology, 266(3), F394-F399.

Marsh-Richard, D. M., Hatzis, E. S., Mathias, C. W., Venditti, N., \& Dougherty, D. M. (2009). Adaptive Visual Analog Scales (AVAS): a modifiable software program for the creation, administration, and scoring of visual analog scales. Behavior Research Methods, 41(1), 99-106.

Maughan, R. J., Watson, P., Cordery, P. A., Walsh, N. P., Oliver, S. J., Dolci, A., Galloway, S. D. (2016). A randomized trial to assess the potential of different beverages to affect hydration status: 

717-723.

Merson, S. J., Maughan, R. J., \& Shirreffs, S. M. (2008). Rehydration with drinks differing in sodium concentration and recovery from moderate exercise-induced hypohydration in man. European Journal of Applied Physiology, 103(5), 585.

Minehan, M. R., Riley, M. D., \& Burke, L. M. (2002). Effect of flavor and awareness of kilojoule content of drinks on preference and fluid balance in team sports. International Journal of Sport Nutrition and Exercise Metabolism, 12(1), 81-92.

Mitchell, J. B., Grandjean, P. W., Pizza, F. X., Starling, R. D., \& Holtz, R. W. (1994). The effect of volume ingested on rehydration and gastric emptying following exercise-induced dehydration. Medicine and Science in Sports and Exercise, 26(9), 1135-1143.

Murray, R., Bartoli, W., Stofan, J., Horn, M., \& Eddy, D. (1999). A comparison of the gastric emptying characteristics of selected sports drinks. International Journal of Sport Nutrition, 9(3), 263-274.

Osterberg, K. L., Pallardy, S. E., Johnson, R. J., \& Horswill, C. A. (2009). Carbohydrate exerts a mild influence on fluid retention following exercise-induced dehydration. Journal of Applied Physiology, 108(2), 245-250.

Passe, D., Horn, M., \& Murray, R. (2000). Impact of beverage acceptability on fluid intake during exercise. Appetite, 35(3), 219-229.

Robertson, G. L. (1974). Vasopressin in osmotic regulation in man. Annual Review of Medicine, 25(1), 315-322.

Savoie, F.A., Kenefick, R. W., Ely, B. R., Cheuvront, S. N., \& Goulet, E. D. (2015). Effect of hypohydration on muscle endurance, strength, anaerobic power and capacity and vertical jumping ability: a meta-analysis. Sports Medicine, 45(8), 1207-1227.

Sawka, M. N., Burke, L. M., Eichner, E. R., Maughan, R. J., Montain, S. J., \& Stachenfeld, N. S. (2007). American College of Sports Medicine position stand. Exercise and fluid replacement. Medicine and Science in Sports and Exercise, 39(2), 377-390. 
Seery, S., \& Jakeman, P. (2016). A metered intake of milk following exercise and thermal dehydration restores whole-body net fluid balance better than a carbohydrate-electrolyte solution or water in healthy young men. British Journal of Nutrition, 116(6), 1013-1021.

Shirreffs, S. M., \& Maughan, R. J. (1998). Volume repletion after exercise-induced volume depletion in humans: replacement of water and sodium losses. American Journal of Physiology-Renal Physiology, 274(5), F868-F875.

Shirreffs, S. M., Watson, P., \& Maughan, R. J. (2007). Milk as an effective post-exercise rehydration drink. British Journal of Nutrition, 98(1), 173-180.

Sommerfield, L. M., McAnulty, S. R., McBride, J. M., Zwetsloot, J. J., Austin, M. D., Mehlhorn, J. D., Utter, A. C. (2016). Validity of Urine specific gravity when compared to plasma osmolality as a measure of hydration status in male and female NCAA collegiate athletes. Journal of strength and conditioning research/National Strength \& Conditioning Association, 30(8), 2219.

Vist, G. E., \& Maughan, R. J. (1995). The effect of osmolality and carbohydrate content on the rate of gastric emptying of liquids in man. The Journal of Physiology, 486(2), 523-531.

Watson, P., Love, T. D., Maughan, R. J., \& Shirreffs, S. M. (2008). A comparison of the effects of milk and a carbohydrate-electrolyte drink on the restoration of fluid balance and exercise capacity in a hot, humid environment. European Journal of Applied Physiology, 104(4), 633-642.

Zimmerman, C. A., Huey, E. L., Ahn, J. S., Beutler, L. R., Tan, C. L., Kosar, S., Madisen, L. (2019). A gut-to-brain signal of fluid osmolarity controls thirst satiation. Nature, 568(7750), 98-102 


\section{$389 \quad$ Figure legends and footnotes}

390 Figure 1. Schematic of experimental protocol investigating the effect of drinking rate on fluid retention following

391 exercise.

Figure 2. Cumulative urine output before and after the test drink ingestion equal to the volume of sweat lost during exercise. A = Part A (Water or Milk ingested over 30 or 90 min, Water 30 (W30); Water 90 (W90); Milk 30 (M30); and Milk 90 (M90)), B = Part B (Water ingested over 15 (DR15), 45 (DR45) or 90 (DR90) mins). $a$, milk significantly different to water. Values are Mean \pm SD.

Figure 3. Net fluid balance responses before and after the test drink ingestion equal to the volume of sweat lost during exercise. A = Part A (Water or Milk ingested over 30 or 90 min, Water 30 (W30); Water 90 (W90); Milk 30 400 (M30); and Milk 90 (M90)), B = Part B (Water ingested over 15 (DR15), 45 (DR45) or 90 (DR90) mins). $a$, milk 401 significantly different to water; $b$, rapid drinking significantly different to metered drinking. Values are Mean \pm SD.

Figure 4. Subjective gastrointestinal ratings of bloatedness, fullness and thirst before and after test drink ingestion equal to the volume of sweat lost during exercise. Part $\mathrm{A}=$ Panels $\mathrm{A}, \mathrm{B}$ and $\mathrm{C}$ and Part B = Panels D, E and F. $a$, 405 milk significantly different to water; $b$, rapid drinking significantly different to metered drinking; $c$, fast ingestion 406 rate significantly different to slow ingestion rate. Values are Mean \pm SEM, where 0 represents 'not at all' and 100

407 represents 'extremely much' for each subjective feeling. 
409 Table 1. Pre-trial conditions and impact of exercise-induced dehydration

\begin{tabular}{|c|c|c|c|c|c|}
\hline Part A & W30 & W90 & M30 & M90 & $p$-value \\
\hline Pre-Ex $U_{S G}$ & $1.015 \pm 0.006$ & $1.015 \pm 0.007$ & $1.013 \pm 0.005$ & $1.014 \pm 0.005$ & 0.35 \\
\hline Pre-Ex P $P_{\text {OSM }}\left(\mathrm{mOsm} \cdot \mathrm{kg}^{-1}\right)$ & $290 \pm 4$ & $292 \pm 5$ & $290 \pm 6$ & $289 \pm 5$ & 0.67 \\
\hline Pre-Ex BM (kg) & $77.10 \pm 9.67$ & $77.27 \pm 9.78$ & $76.77 \pm 9.73$ & $76.57 \pm 9.52$ & 0.28 \\
\hline Ex Duration (min) & $70 \pm 14$ & $70 \pm 13$ & $70 \pm 13$ & $70 \pm 12$ & 0.86 \\
\hline BM Loss (kg) & $1.46 \pm 0.28$ & $1.42 \pm 0.30$ & $1.43 \pm 0.32$ & $1.46 \pm 0.29$ & 0.79 \\
\hline BM Loss (\%) & $1.9 \pm 0.3$ & $1.9 \pm 0.4$ & $1.9 \pm 0.4$ & $1.9 \pm 0.3$ & 0.82 \\
\hline Part B & DR15 & DR45 & DR90 & & $p$-value \\
\hline Pre-Ex $U_{\text {OSM }}$ & $477 \pm 218$ & $474 \pm 178$ & $443 \pm 185$ & & 0.76 \\
\hline Pre-Ex P ${ }_{\text {OSM }}\left(\mathrm{mOsm} \cdot \mathrm{kg}^{-1}\right)$ & $303 \pm 5$ & $302 \pm 3$ & $302 \pm 5$ & & 0.36 \\
\hline Pre-Ex BM (kg) & $71.60 \pm 9.90$ & $71.54 \pm 10.15$ & $71.31 \pm 10.08$ & & 0.39 \\
\hline Ex Duration (min) & $79 \pm 12$ & $81 \pm 13$ & $80 \pm 11$ & & 0.62 \\
\hline BM Loss (kg) & $1.46 \pm 0.35$ & $1.51 \pm 0.33$ & $1.45 \pm 0.32$ & & 0.30 \\
\hline BM Loss (\%) & $2.0 \pm 0.4$ & $2.1 \pm 0.2$ & $2.0 \pm 0.3$ & & 0.61 \\
\hline
\end{tabular}

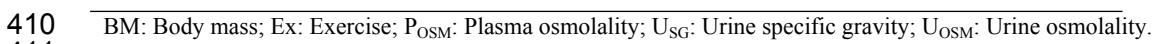

411 Values are Mean \pm SD. 
413 Table 2. Test-retest trial data (Part B: pooled from DR15 and DR45)

\begin{tabular}{lccc}
\hline & Initial Trial & Repeat Trial & p-value \\
\hline Pre-Trial Conditions & & & 0.30 \\
\hline Pre-Ex U OSM & $483 \pm 197$ & $479 \pm 197$ & 0.81 \\
Pre-Ex POSM $\left(\mathrm{mOsm} \cdot \mathrm{kg}^{-1}\right)$ & $307 \pm 5$ & $307 \pm 7$ & 0.30 \\
Pre-Ex BM (kg) & $72.56 \pm 11.10$ & $72.38 \pm 10.94$ & 0.34 \\
Ex Duration (min) & $80.0 \pm 13.5$ & $80.8 \pm 13.1$ & 0.62 \\
BM Loss (kg) & $1.43 \pm 0.32$ & $1.39 \pm 0.39$ & 0.07 \\
\hline Fluid Retention Data & & & 0.69 \\
\hline Cumulative urine output $(\mathrm{g})$ & $792 \pm 280$ & $704 \pm 175$ & 0.38 \\
$\mathrm{U}_{\text {OSM }} 180$ min after drinking started $\left(\mathrm{mOsm} \cdot \mathrm{kg}^{-1}\right)$ & $297 \pm 75$ & $281 \pm 127$ & 0.21 \\
P $_{\mathrm{OSM}} 180$ min after drinking started $\left(\mathrm{mOsm} \cdot \mathrm{kg}^{-1}\right)$ & $303 \pm 4$ & $302 \pm 4$ & $55.0 \pm 7.5$ \\
Fluid retention (\%) & $52.8 \pm 7.0$ & & \\
\hline
\end{tabular}

$414 \quad$ Values are mean \pm SD.

415

416

417

418 
422

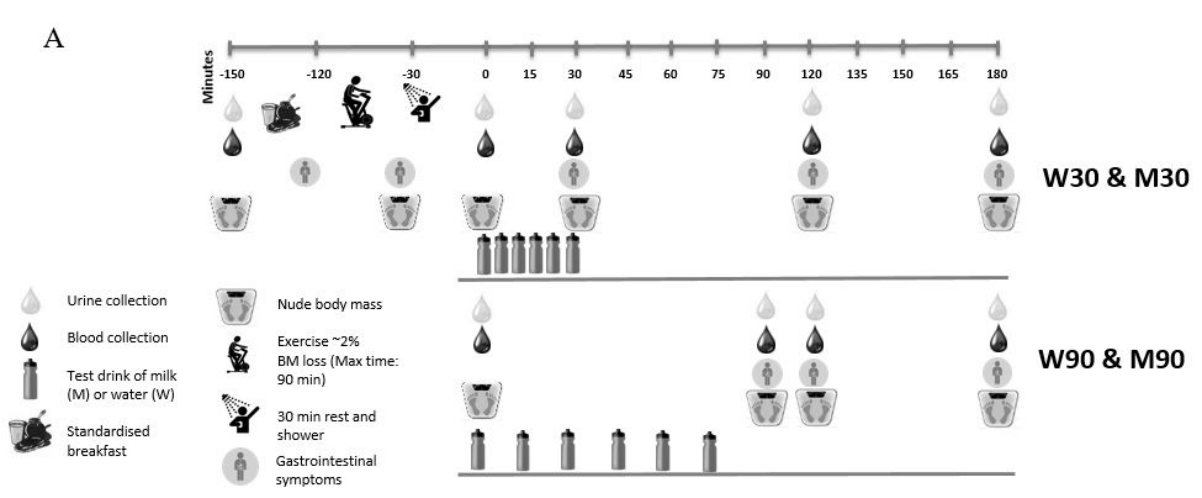

423

424

425

426

427

428

429

430

431

432

433

434

435

436

Figure 1

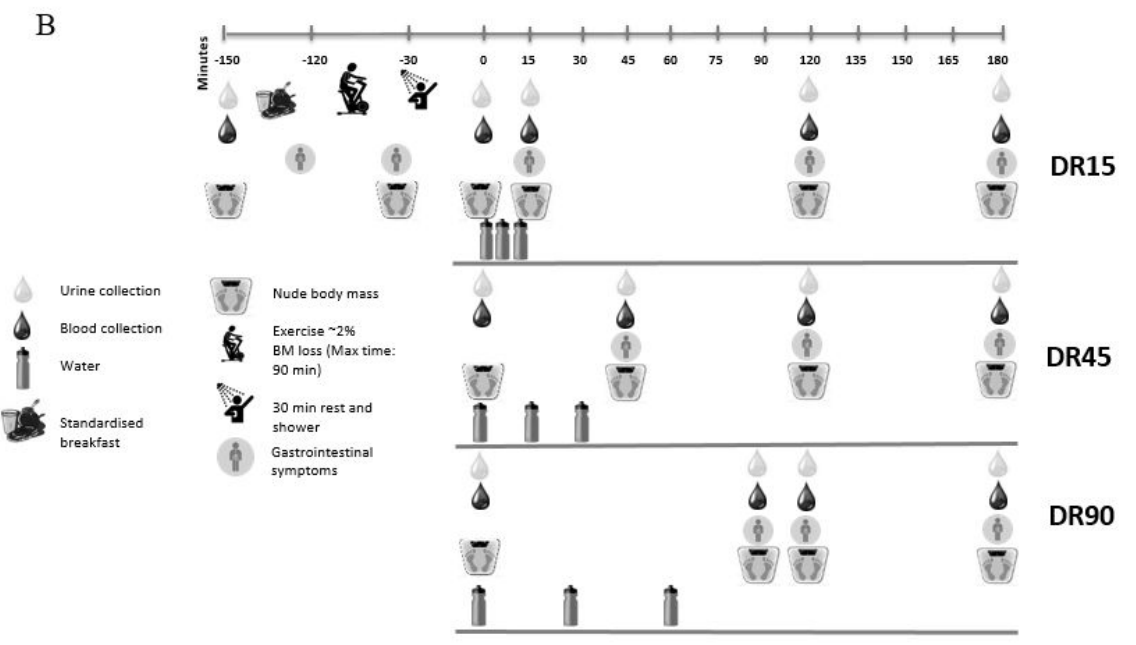


437

438

Figure 2
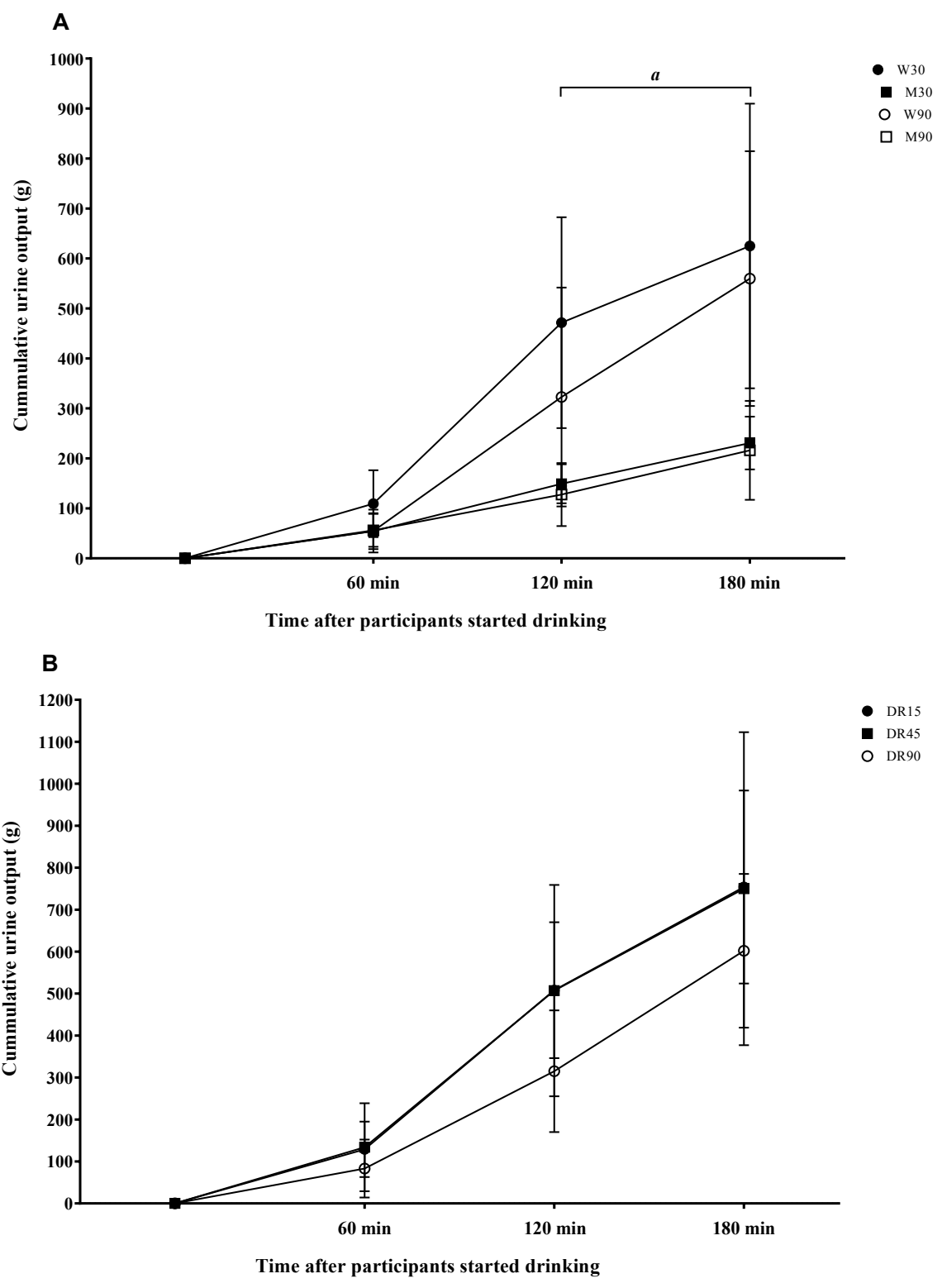


\section{Figure 3}

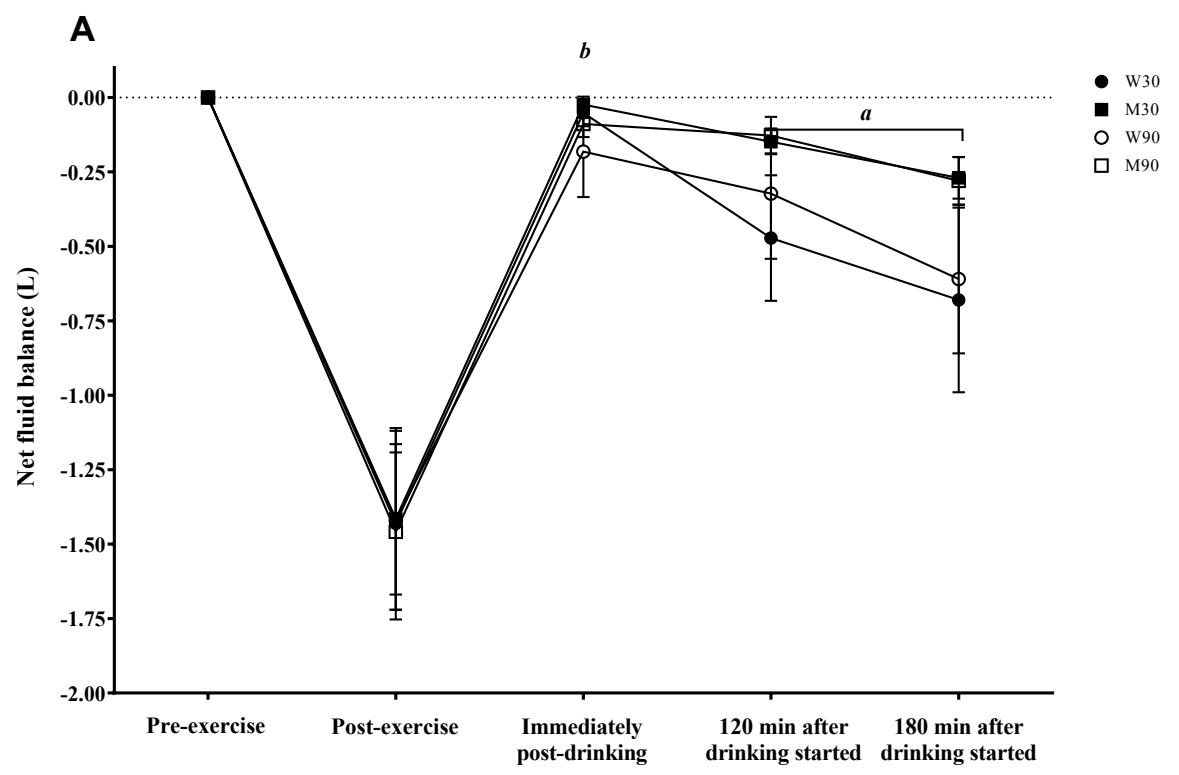

\section{B}

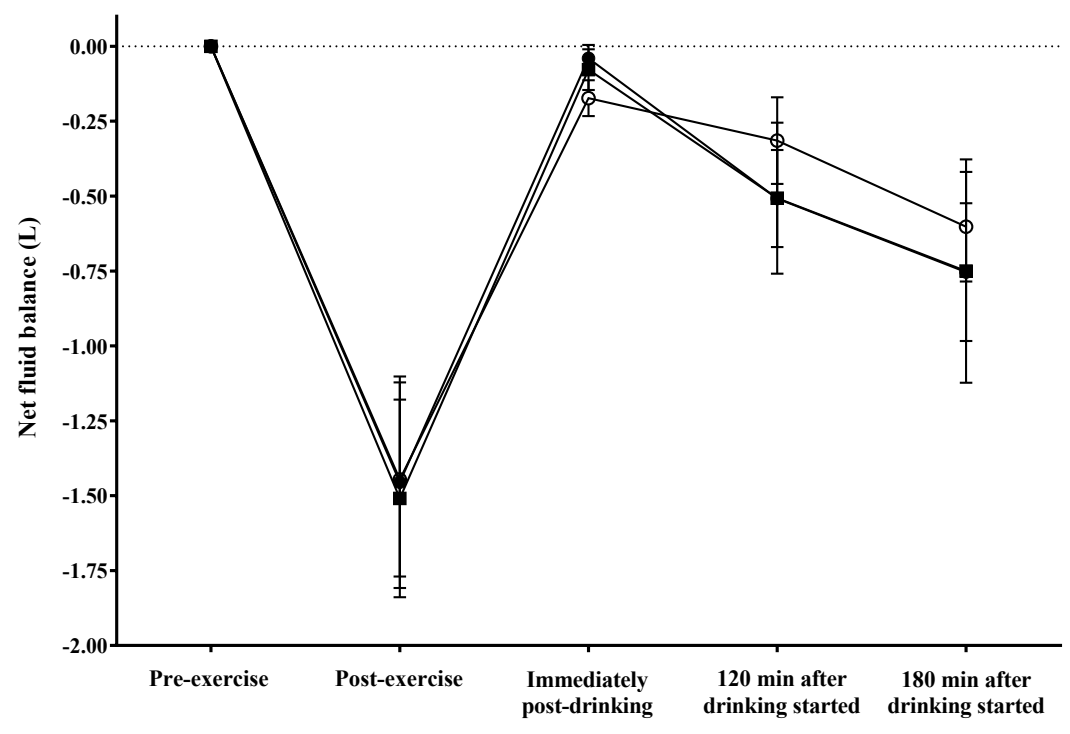


445

446

\section{Figure 4}

A

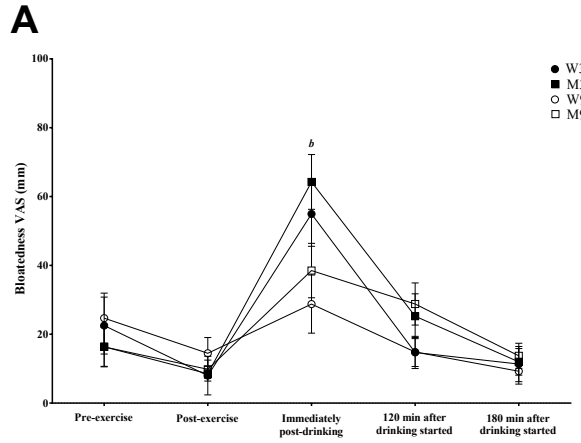

B

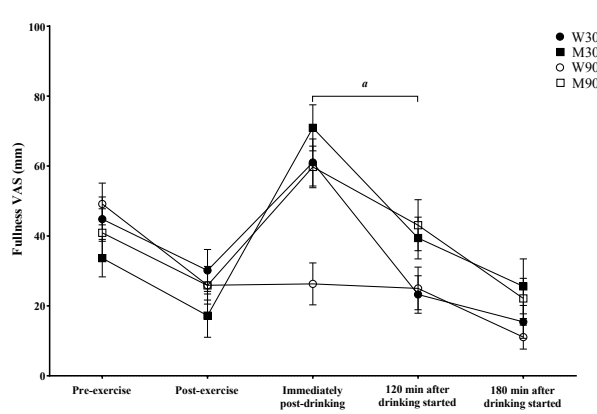

C

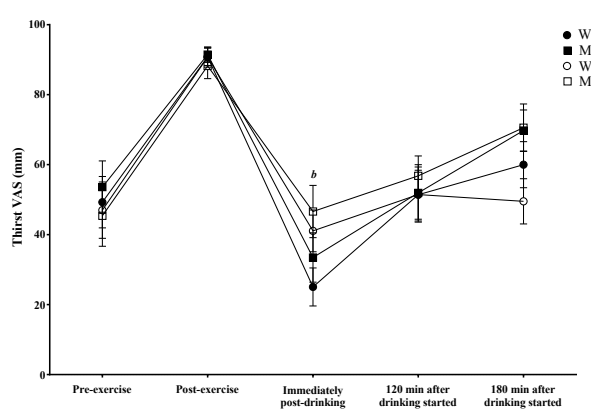

D

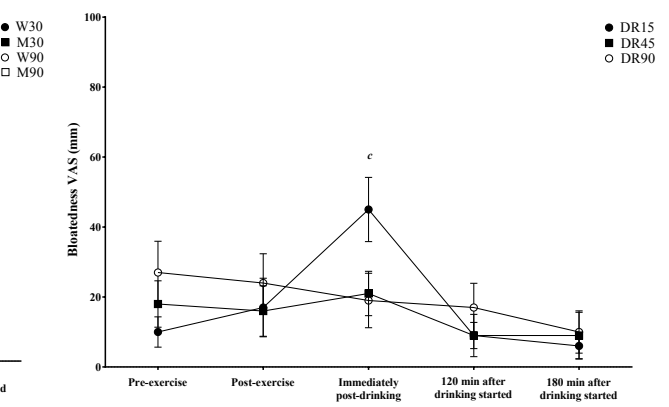

E

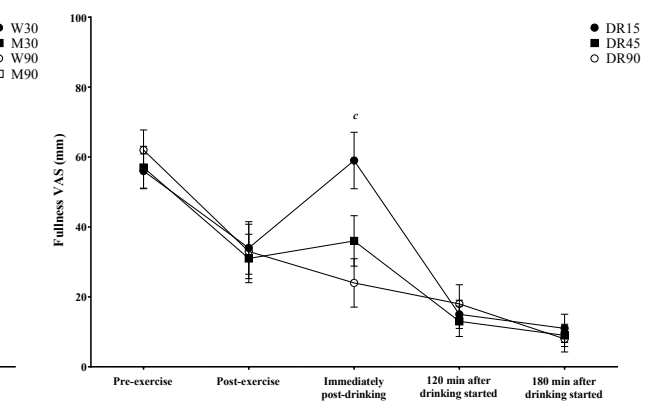

$\mathbf{F}$

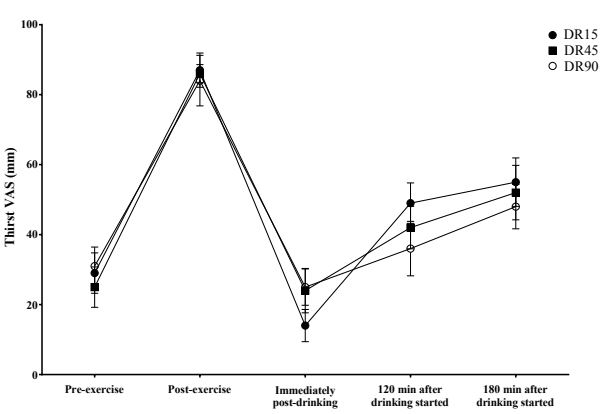

447

448 


\section{Figure 1}

A

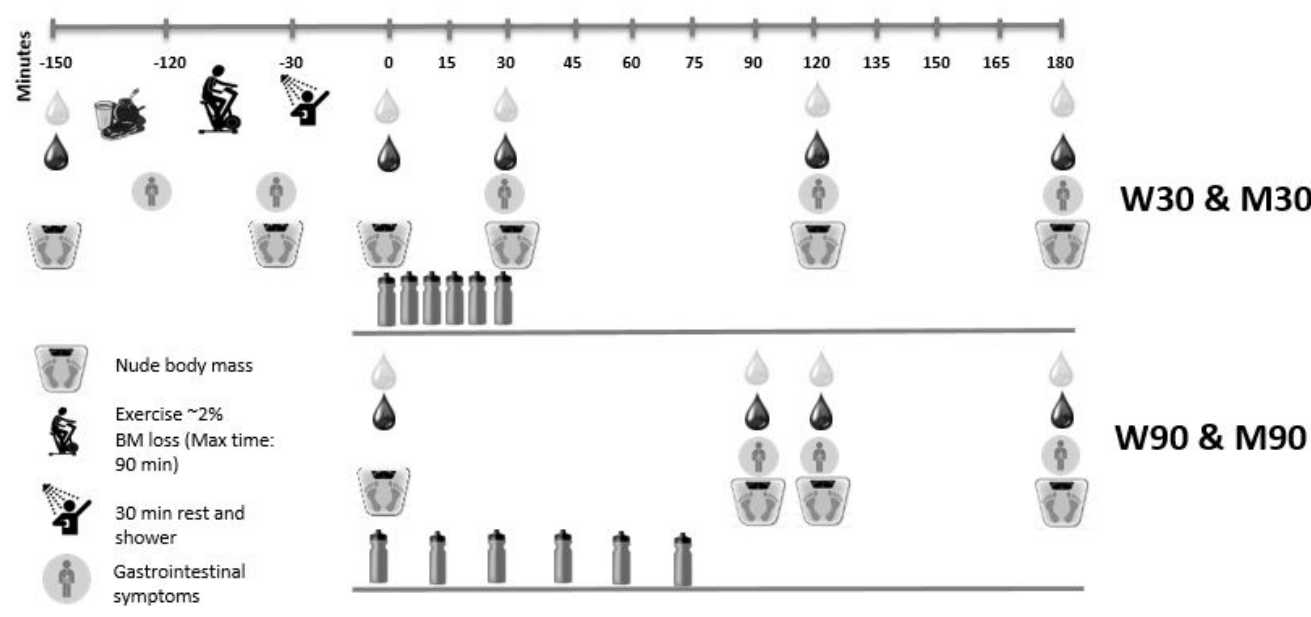

B

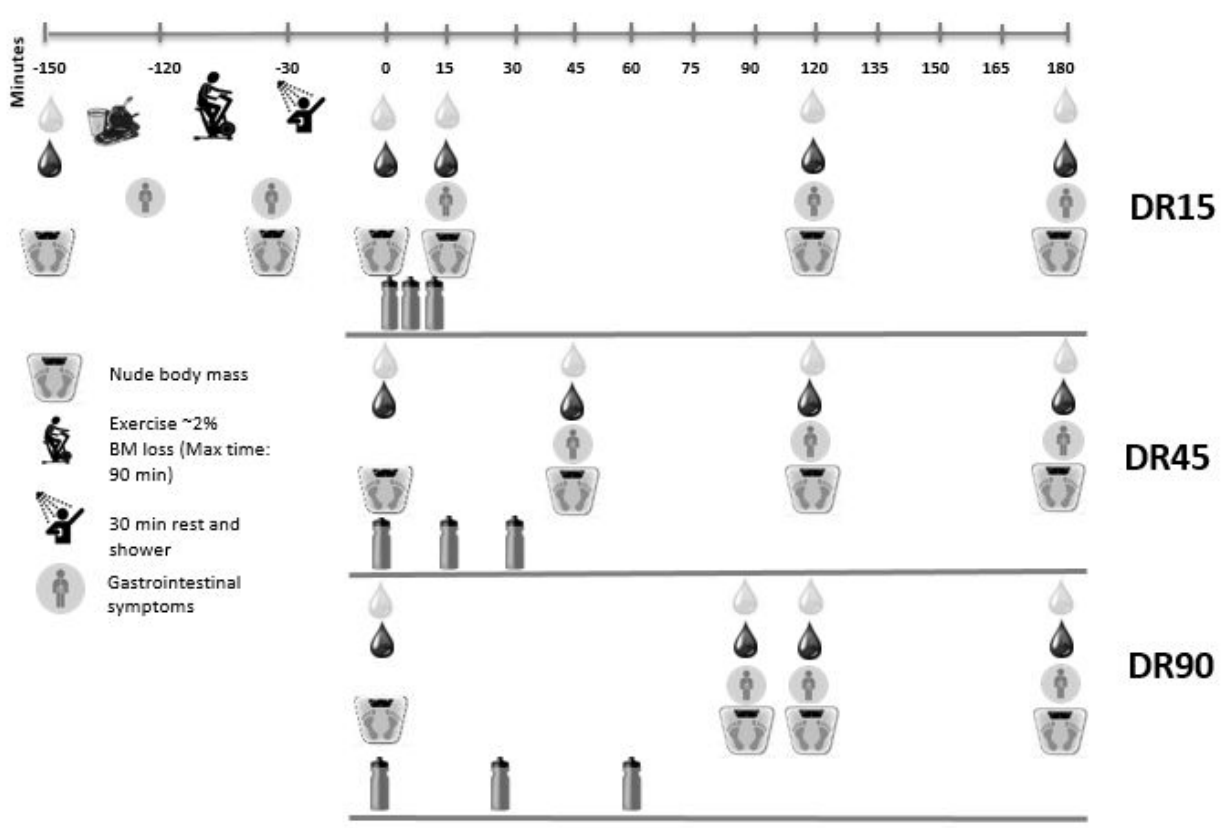


Figure 2

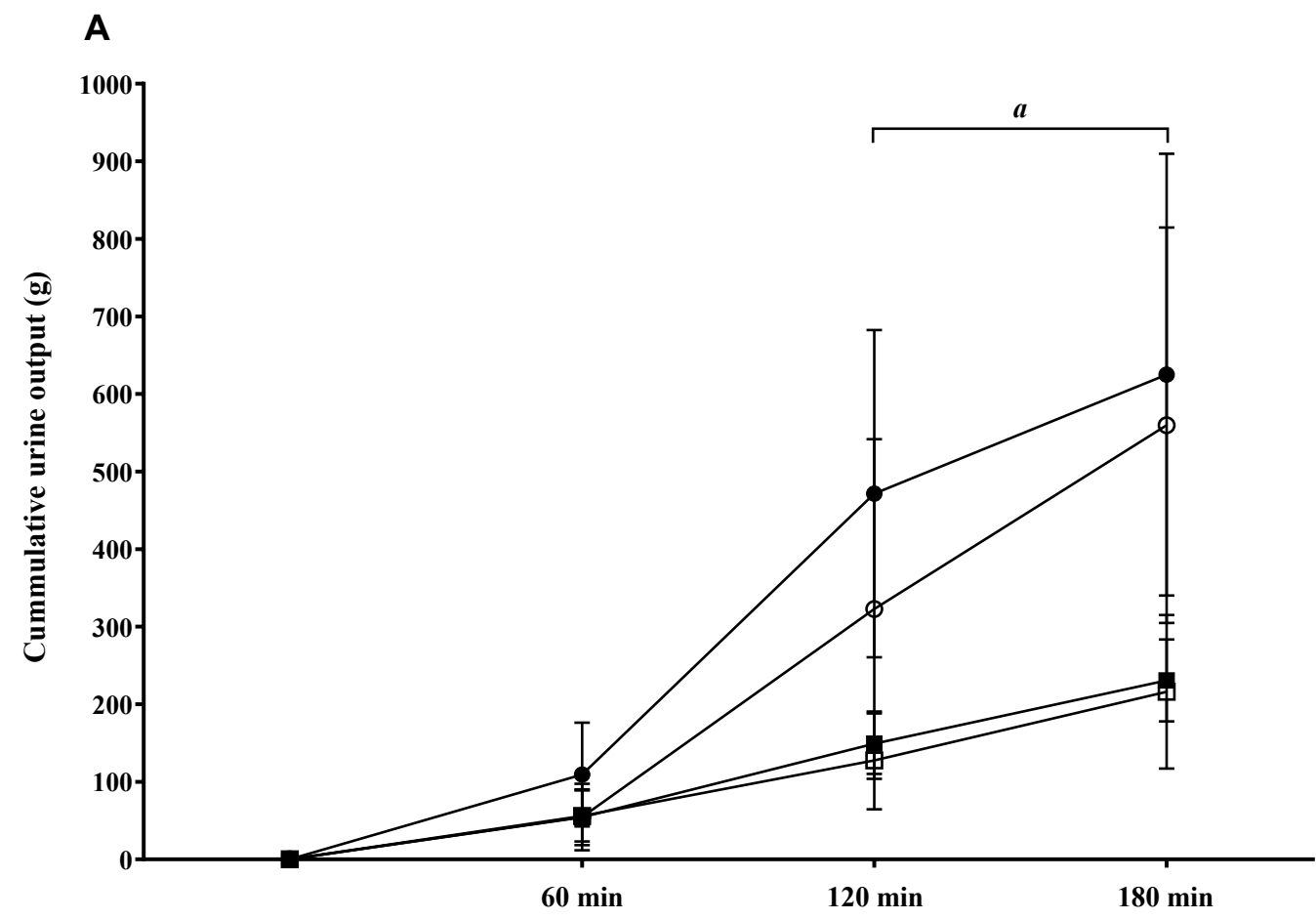

Time after participants started drinking

\section{B}

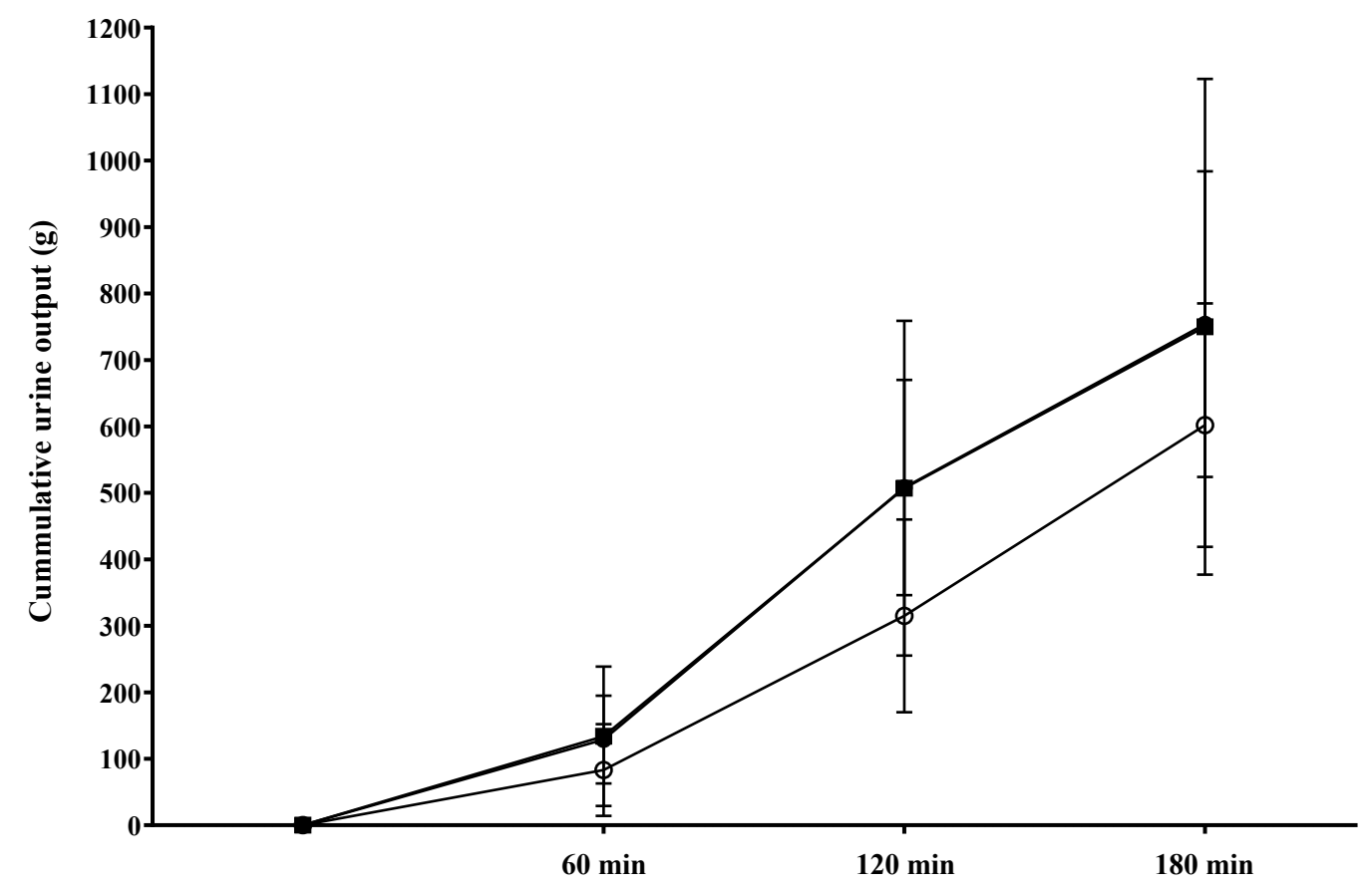

Time after participants started drinking 
Figure 3

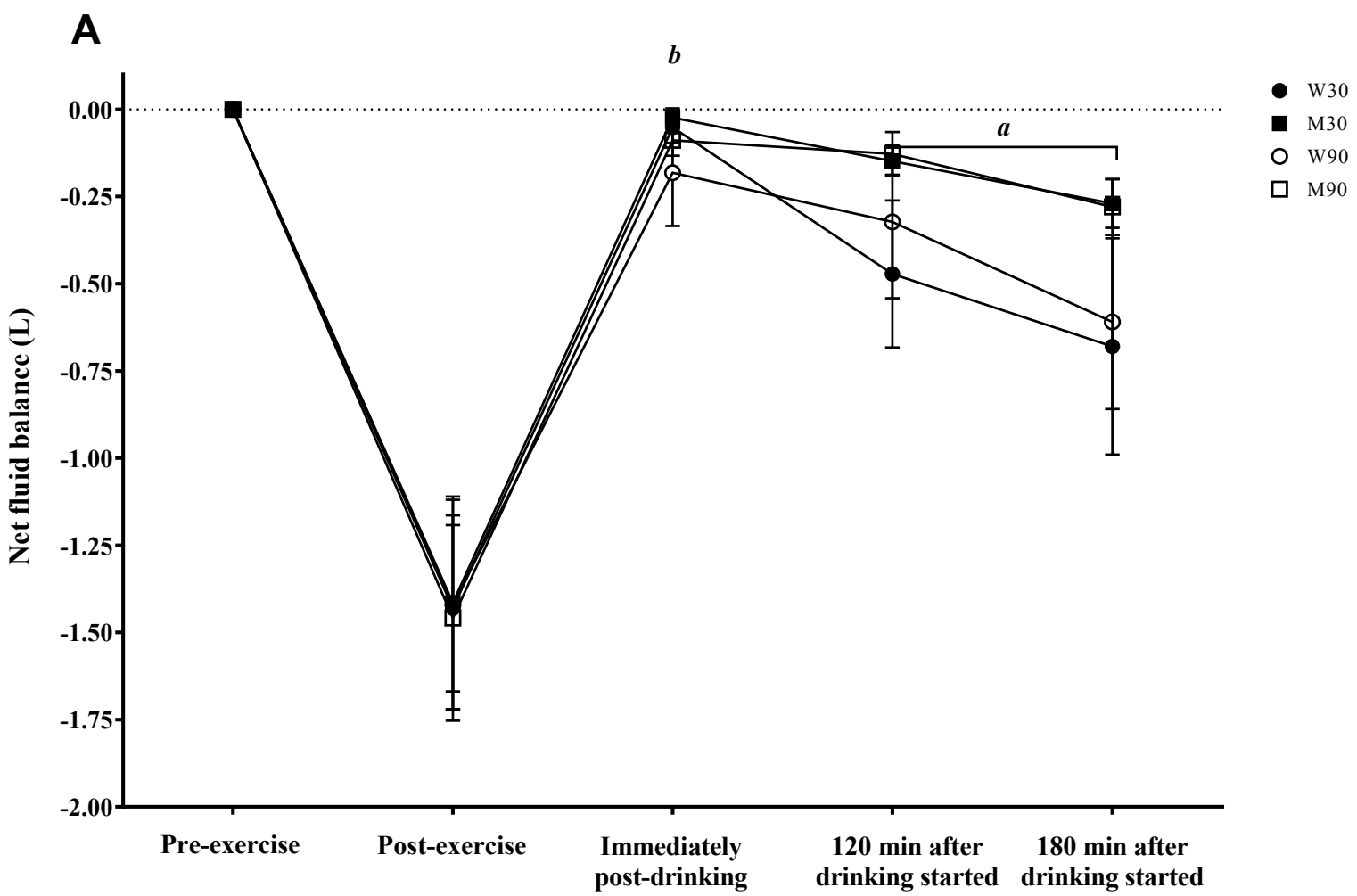

B

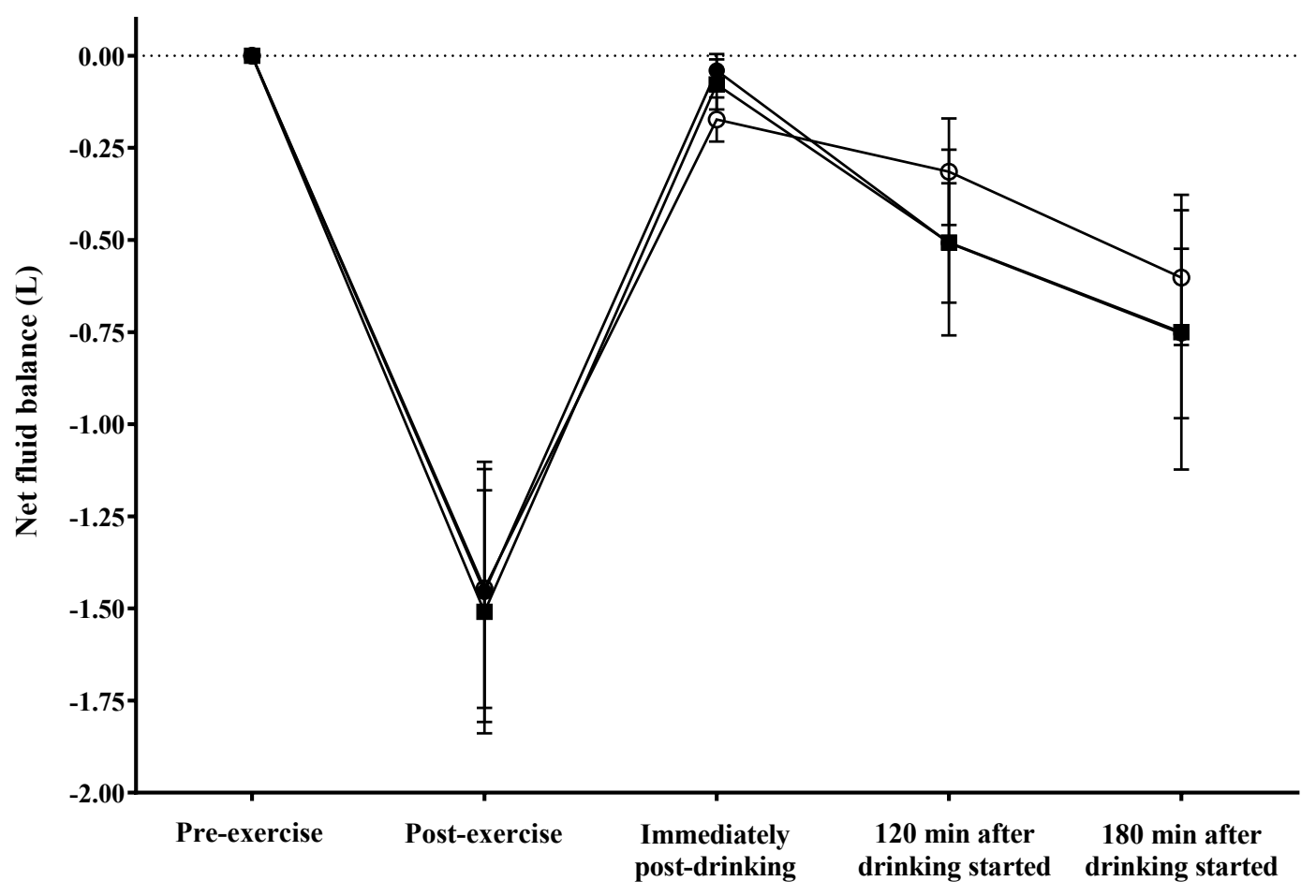




\section{Figure 4}

A

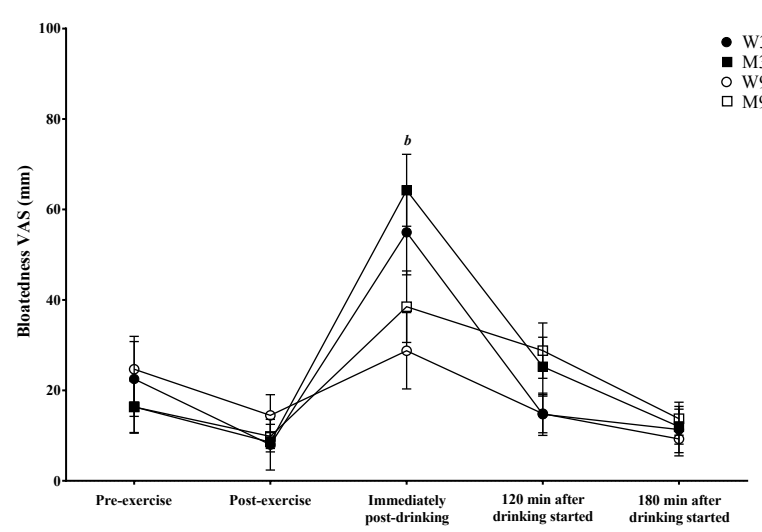

B

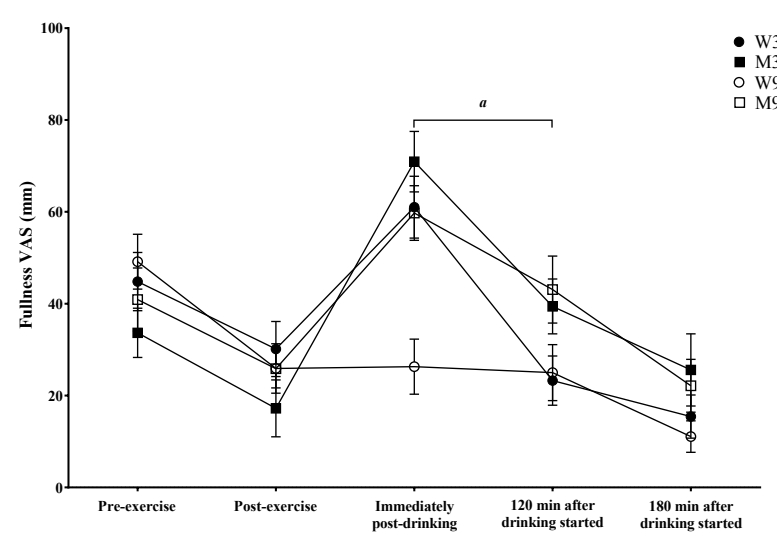

C

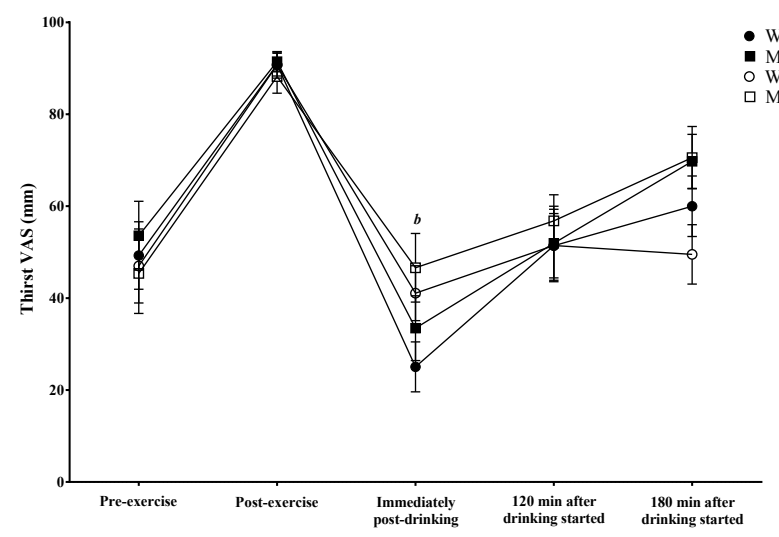

D

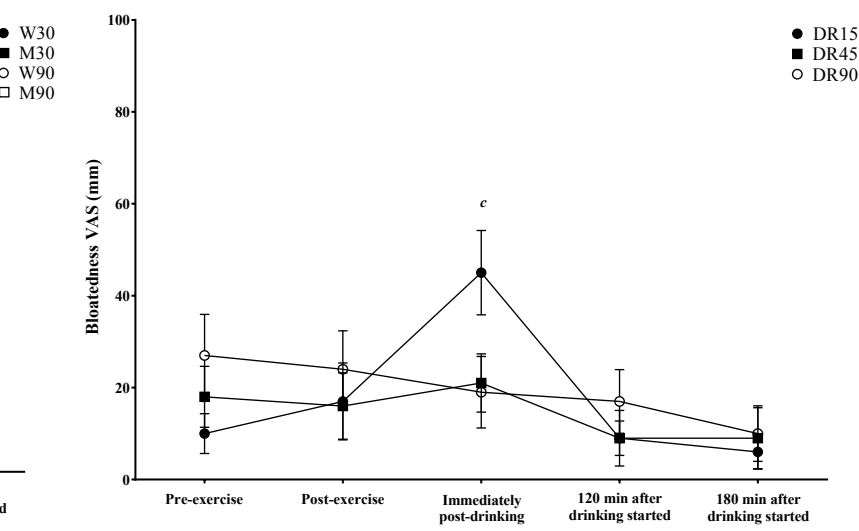

E

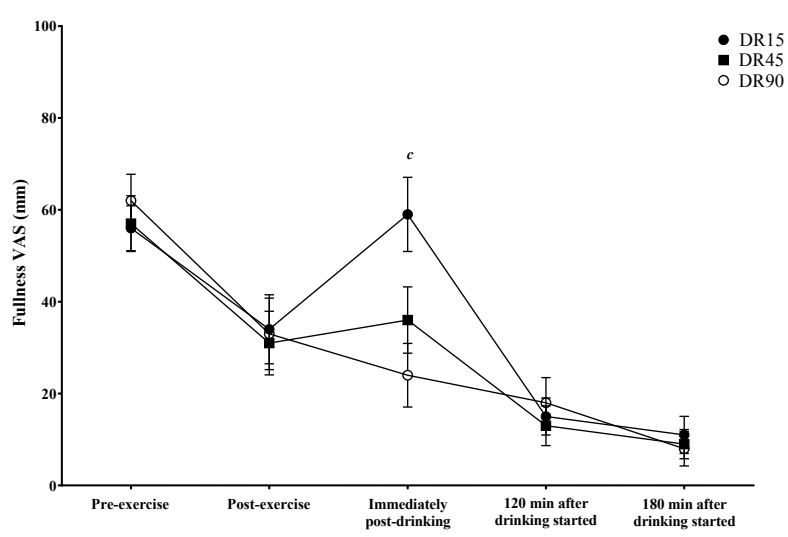

$\mathbf{F}$

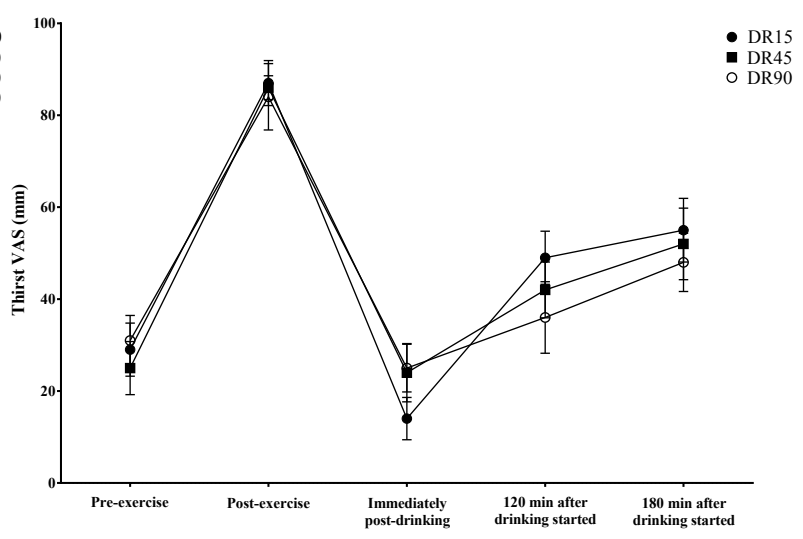


Table 1. Pre-trial conditions and impact of exercise-induced dehydration

\begin{tabular}{lccccc}
\hline Part A & W30 & W90 & M30 & M90 & $p$-value \\
\hline Pre-Ex USG & $1.015 \pm 0.006$ & $1.015 \pm 0.007$ & $1.013 \pm 0.005$ & $1.014 \pm 0.005$ & 0.35 \\
Pre-Ex POSM $\left(\mathrm{mOsm} \cdot \mathrm{kg}^{-1}\right)$ & $290 \pm 4$ & $292 \pm 5$ & $290 \pm 6$ & $289 \pm 5$ & 0.67 \\
Pre-Ex BM (kg) & $77.10 \pm 9.67$ & $77.27 \pm 9.78$ & $76.77 \pm 9.73$ & $76.57 \pm 9.52$ & 0.28 \\
Ex Duration (min) & $70 \pm 14$ & $70 \pm 13$ & $70 \pm 13$ & $70 \pm 12$ & 0.86 \\
BM Loss (kg) & $1.46 \pm 0.28$ & $1.42 \pm 0.30$ & $1.43 \pm 0.32$ & $1.46 \pm 0.29$ & 0.79 \\
BM Loss (\%) & $1.9 \pm 0.3$ & $1.9 \pm 0.4$ & $1.9 \pm 0.4$ & $1.9 \pm 0.3$ & 0.82 \\
\hline Part B & $\mathbf{D R 1 5}$ & $\mathbf{D R 4 5}$ & $\mathbf{D R 9 0}$ & & $\boldsymbol{p}$-value \\
\hline Pre-Ex U & $477 \pm 218$ & $474 \pm 178$ & $443 \pm 185$ & & 0.76 \\
Pre-Ex Posm $\left(\mathrm{mOsm} \cdot \mathrm{kg}^{-1}\right)$ & $303 \pm 5$ & $302 \pm 3$ & $302 \pm 5$ & & 0.36 \\
Pre-Ex BM (kg) & $71.60 \pm 9.90$ & $71.54 \pm 10.15$ & $71.31 \pm 10.08$ & & 0.39 \\
Ex Duration (min) & $79 \pm 12$ & $81 \pm 13$ & $80 \pm 11$ & & 0.62 \\
BM Loss (kg) & $1.46 \pm 0.35$ & $1.51 \pm 0.33$ & $1.45 \pm 0.32$ & & 0.30 \\
BM Loss (\%) & $2.0 \pm 0.4$ & $2.1 \pm 0.2$ & $2.0 \pm 0.3$ & & 0.61
\end{tabular}

BM: Body mass; Ex: Exercise; $\mathrm{P}_{\mathrm{OSM}}$ : Plasma osmolality; $\mathrm{U}_{\mathrm{SG}}$ : Urine specific gravity; $\mathrm{U}_{\mathrm{OSM}}$ : Urine osmolality. Values are Mean \pm SD. 
Table 2. Test-retest trial data (Part B: pooled from DR15 and DR45)

\begin{tabular}{|c|c|c|c|}
\hline & Initial Trial & Repeat Trial & p-value \\
\hline \multicolumn{4}{|l|}{ Pre-Trial Conditions } \\
\hline Pre-Ex U USM & $483 \pm 197$ & $479 \pm 197$ & 0.30 \\
\hline Pre-Ex $P_{\text {OSM }}\left(\mathrm{mOsm} \cdot \mathrm{kg}^{-1}\right)$ & $307 \pm 5$ & $307 \pm 7$ & 0.81 \\
\hline Pre-Ex BM (kg) & $72.56 \pm 11.10$ & $72.38 \pm 10.94$ & 0.30 \\
\hline Ex Duration (min) & $80.0 \pm 13.5$ & $80.8 \pm 13.1$ & 0.34 \\
\hline BM Loss (kg) & $1.43 \pm 0.32$ & $1.39 \pm 0.39$ & 0.62 \\
\hline \multicolumn{4}{|l|}{ Fluid Retention Data } \\
\hline Cumulative urine output (g) & $792 \pm 280$ & $704 \pm 175$ & 0.07 \\
\hline $\mathrm{U}_{\mathrm{OSM}} 180 \mathrm{~min}$ after drinking started $\left(\mathrm{mOsm} \cdot \mathrm{kg}^{-1}\right)$ & $297 \pm 75$ & $281 \pm 127$ & 0.69 \\
\hline $\mathrm{P}_{\mathrm{OSM}} 180 \mathrm{~min}$ after drinking started $\left(\mathrm{mOsm} \cdot \mathrm{kg}^{-1}\right)$ & $303 \pm 4$ & $302 \pm 4$ & 0.38 \\
\hline Fluid retention (\%) & $52.8 \pm 7.0$ & $55.0 \pm 7.5$ & 0.21 \\
\hline
\end{tabular}

Values are mean \pm SD. 